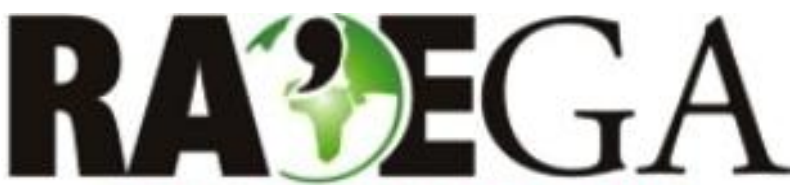

O ESPAÇO GEOGRÁFICO EM ANÁLISE

\title{
A ORGANIZAÇÃO ESPACIAL DE ITUIUTABA/MG MEDIADA PELA CULTURA DA CANA DE AÇÚCAR
}

\section{THE SPACE ORGANIZATION OF ITUIUTABA / MG MEDIATED BY THE CULTURE OF SUGAR CANE}

\author{
Eduardo Marques Silveira ${ }^{1}$, Meri Lourdes Bezzi ${ }^{2}$
}

\section{RESUMO}

As transformações no espaço agrário brasileiro são inerentes a sua organização espacial, pois ao longo de sua história, foram diversos os fatores determinantes para o seu desenvolvimento. Entre os elementos dinamizadores, pode-se destacar a modernização da agricultura, a qual se intensificou a partir da década de 1980. Esta também está presente na Microrregião Geográfica de Ituiutaba (MRG 017), foco de estudo desta pesquisa. O espaço agrário da MRG em análise foi se alterando, com o decorrer do tempo, o que influenciou diretamente no meio produtivo das unidades territoriais que a compõem. O presente estudo tem como objetivo geral analisar as principais transformações causadas pela inserção do agronegócio da cana de açúcar nos municípios que compõem a Microrregião Geográfica de Ituiutaba/MG. Especificamente, buscou-se: a) compreender a influência da modernização da agricultura; b) verificar as políticas públicas que atuaram na inserção deste cultivar e c) analisar as principais problemáticas envoltas na produção da cana de açúcar. Metodologicamente o trabalho está dividido em etapas sendo elas: 1) pesquisa bibliográfica; 2) trabalho de campo; 3) coleta de dados e 4) análise dos resultados. Entende-se que a cultura analisada ocasionou grandes transformações no meio rural da MRG em estudo, atrelada ao processo de mecanização da agricultura e o incentivo de políticas governamentais para que ocorresse a inserção deste cultivar no espaço agrário supracitado.

Palavras chave: Modernização da agricultura; cana de açúcar; Microrregião Geográfica de Ituiutaba-MG.

\section{ABSTRACT}

The transformations in the Brazilian agrarian space are inherent to its spatial organization, because throughout history, were the determining factors for its development. Among the dynamic elements, is the modernization of agriculture, which has intensified since the 1980s. It is also present in the Geographic Micro-region Ituiutaba (MRG 017), the focus of this research. The agrarian space of GMR in analysis was changing, with the passage of time, which directly influenced the productive environment of the territorial units that compose it. The present study has as general objective to analyze the main transformations caused by the insertion of sugarcane agribusiness in the municipalities that compose the Geographic Micro-region of Ituiutaba / state of Minas Gerais, Brazil. Specifically, we sought to: a) understand the influence of the modernization of agriculture; B) to verify the public policies that took part in the insertion of this cultivation and c) to analyze the main problems involved in the production of sugar cane. Methodologically the work is divided into stages: 1) bibliographic research; 2) fieldwork; 3) data collection and 4) analysis of results. It is understood that the analyzed crop, caused great transformations in the rural environment of the GMR under study. Therefore, the process of mechanization of agriculture and the incentive of governmental policies encouraged the occurrence of the insertion of this cultivation in the agrarian space.

Keywords: Modernization of agriculture; Sugar cane; Microrregião Geográfica de Ituiutaba-MG.

\footnotetext{
${ }^{1}$ Universidade Federal de Santa Maria,Santa Maria/RS, email: marqueseduardos@hotmail.com

${ }^{2}$ Universidade Federal de Santa Maria,Santa Maria/RS, email: meribezzi@yahoo.com.br
} 


\section{A ORGANIZAÇÃO ESPACIAL DE ITUIUTABA/MG MEDIADA PELA CULTURA DA CANA DE AÇÚCAR}

\section{INTRODUÇÃO}

A ciência geográfica tem como preocupação central o estudo das relações entre a sociedade e a natureza, pois é através destas que ocorrem as transformações espaciais, ou seja, as complexas relações presentes no espaço. Com base nas mudanças é que o ele se organiza e reorganiza resultando em recortes espaciais distintos. Assim, as transformações que ocorrem tanto no meio rural quanto no urbano são provenientes dos elementos socioespaciais originados em diferentes temporalidades.

A Microrregião Geográfica de Ituiutaba/MG (MRG 017), foco de estudo desta pesquisa, é um exemplo das modificações presentes no meio rural e da evolução que estas podem proporcionar. A MRG de Ituiutaba, ao longo do tempo, passou por mudanças em seu meio agrário, reestruturando o cenário produtivo de suas unidades territoriais, sendo elas: Ituiutaba, Santa Vitória, Gurinhatã, Ipiaçu, Cachoeira Dourada e Capinópolis. (FIGURA 1).

Destaca-se que o desenvolvimento agrário brasileiro é proveniente de transformações, ou seja, da reorganização espacial resultante de diferentes atores sociais, políticos e econômicos que geram a inserção de novos elementos que tendem a modificar o espaço no decorrer do tempo. Um exemplo disto são as alterações provenientes das mudanças de produção que ocorrem nos recortes espaciais em estudo.

A Microrregião Geográfica de Ituiutaba está localizada na Mesorregião Geográfica do Triângulo Mineiro/Alto Paranaíba (MSG 3105), se situa a oeste do Estado de Minas Gerais e apresenta uma extensão territorial de 8.736,204 $\mathrm{km}^{2}$. Atualmente, possui uma população de 150.977 habitantes, com densidade demográfica de 17,29 hab./km. (IBGE, 2015).

Ressalta-se que a MRG de Ituiutaba apresenta excelente posição geográfica, pois possui interligações com importantes rodovias brasileiras, como as BR's 364, 365, 461, 226, as quais facilitam o escoamento de produtos e a locomoção de pessoas. A MRG em estudo faz divisa com Goiás, estando próxima dos estados de São Paulo e Mato Grosso do Sul.

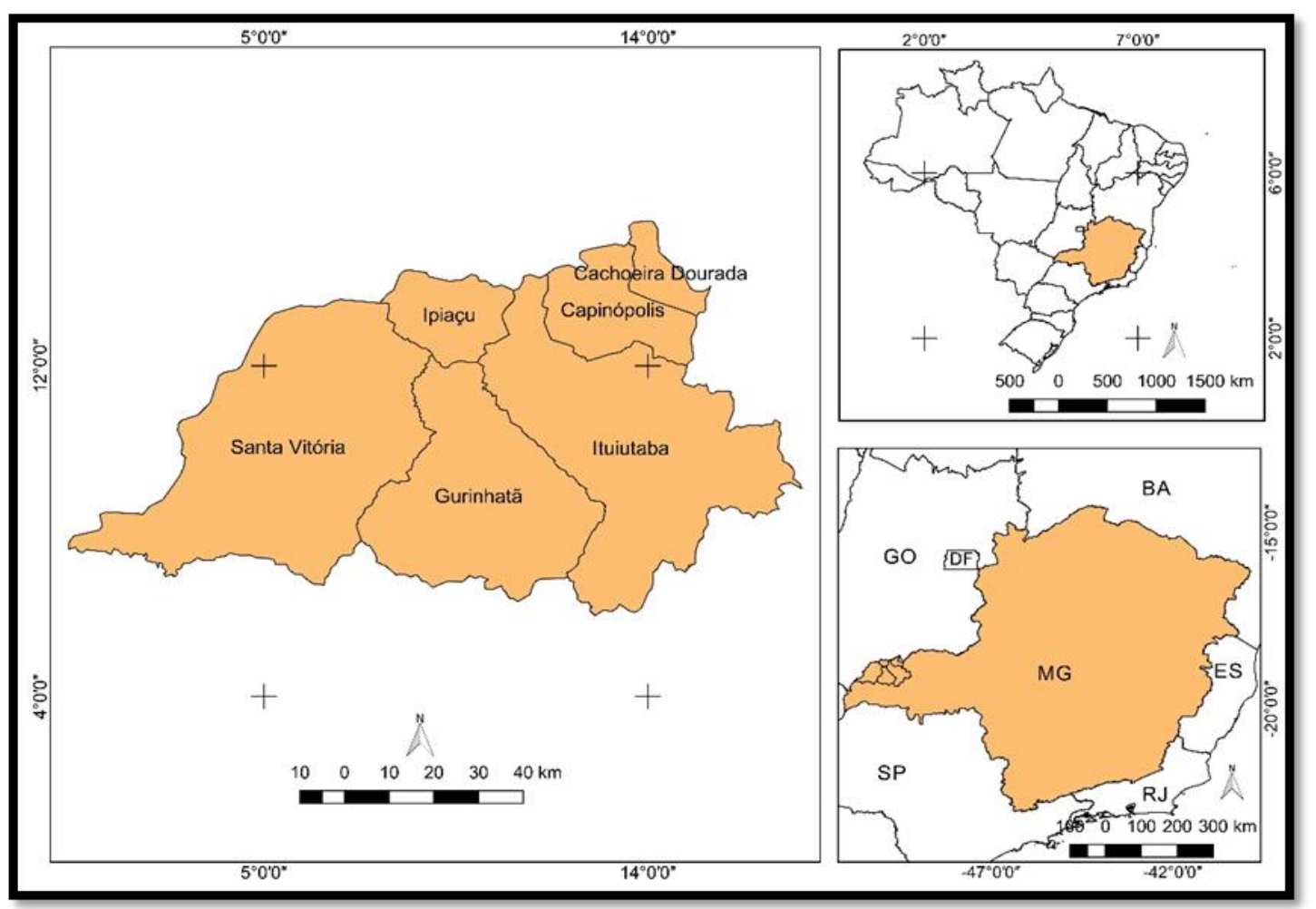

Figura 1 - Localização da Microrregião Geográfica de Ituiutaba/Minas Gerais.

Fonte: Base digital do Instituto Brasileiro de Geografia e Estatística - IBGE (2010). 


\section{A ORGANIZAÇÃO ESPACIAL DE ITUIUTABA/MG MEDIADA PELA CULTURA DA CANA DE AÇÚCAR}

Ao longo da história, esse recorte espacial passou por diversas reorganizações espaciais no âmbito rural/local. Tal fato se refere aos ciclos produtivos agropecuários. Nesse cenário, o município de Ituiutaba, na década 1970 foi considerado "A capital do arroz no Brasil". (OLIVEIRA, 2003, p. 60).

No entanto, com o decorrer do tempo, houve um redirecionamento produtivo, alicerçado pelas políticas e ações tanto internas quanto externas de origem públicas e privadas, as quais foram responsáveis por mudanças estratégicas nos modelos produtivos regionais/locais.

Cabe enfatizar que a modernização da agricultura foi um dos fatores responsáveis pelas novas reorganizações espaciais presentes no espaço rural da Microrregião Geográfica de Ituiutaba. Estas transformações ocorreram após a Segunda Guerra Mundial, pois foi neste período que se teve um maior avanço tecnológico, proporcionando com que também o campo passasse a usufruir de novas técnicas e, consequentemente de mudanças espaciais significativas.

Outros elementos dinamizadores do desenvolvimento e da organização do espaço agrário são o capital e o Estado, sendo os principais fatores de incremento e de transformação do meio rural. Salienta-se que eles estão interligados ao processo de desenvolvimento, ou seja, é comum eles trabalharem juntos. Cita-se, por exemplo, as iniciativas provenientes do governo para a atração de novas empresas para o país, tais como a Monsanto, Souza Cruz, Nestlé entre outras. Assim, entende-se que o Estado e o capital são fundamentais para a produção agrária brasileira, pois é através destes que se tem aumentado a produtividade das culturas, bem como a consolidação de indústrias que dinamizam a produção agrícola.

Através destas políticas e de projetos idealizados pelo Estado, teve-se como resultado a introdução de novos cultivos, como a soja, na década de 1980 e a retomada da expansão da produção de cana de açúcar, a partir de 2000, entre outras que alteraram o cenário econômico rural/local da MRG de Ituiutaba.

\section{MATERIAIS E MÉTODOS}

Para um melhor entendimento dos processos teórico-metodológicos da pesquisa, estes foram estruturados em etapas, as quais permitiram trabalhar de forma organizacional, visando atingir os objetivos propostos.

A fase inicial da pesquisa correspondeu à estruturação da matriz teórica e à definição do método científico do trabalho, ou seja, se procurou trabalhar inicialmente com a revisão bibliográfica, sendo esta pautada nos conceitos norteadores da pesquisa, como a modernização da agricultura, as políticas públicas e/ou privadas para o desenvolvimento do meio agrário e a organização e/ou reorganização espacial. Através destes conceitos, foi possível compreender as questões relacionadas com o setor agrário da Microrregião Geográfico de Ituiutaba (MRG017).

Por compreender que o método é um caminho para respostas, a presente pesquisa tem como método investigativo o dialético ${ }^{3}$, entendendo que ele é um dos responsáveis pela composição e organização do espaço, compreendendo-o como um processo que apresenta mudanças e, consequentemente, gerando novas organizações espaciais no decorrer do tempo.

Desta forma, compreende-se que o arranjo produtivo da Microrregião Geográfica de Ituiutaba ocorreu através das modificações que a

\footnotetext{
${ }^{3}$ Entende-se que o método dialético, busca em sua essência analisar, não somente os desenvolvimentos socioeconômicos de uma determinada área, mas sim as problemáticas envoltas neste processo de aprimoramento econômico. Entretanto, este artigo se primou apenas pela análise histórico dialética da produção da cana de açúcar, na Microrregião Geográfica de Ituiutaba, sendo assim observado apenas a sua produtividade ao longo do recorte temporal supracitado, e não ocorrendo um aprofundamento das questões sociais relacionas a cana de açúcar.
} 


\section{A ORGANIZAÇÃO ESPACIAL DE ITUIUTABA/MG MEDIADA PELA CULTURA DA CANA DE AÇÚCAR}

mesma apresentou ao longo de sua história, uma vez que foi possível verificar os agentes transformadores tais como os fatores econômicos, as políticas públicas e sociais, a inserção de novas culturas, entre outros, que foram organizando e/ou reorganizando as unidades territoriais que integram a MRG em foco. (CARGNIN, 2009, p. 34).

Realizada a primeira etapa do trabalho, a segunda correspondeu ao trabalho de campo. Nesta etapa se teve como preocupação central verificar a organização/reorganização da MRG em questão. Desta maneira, procurou-se entender como a mesma alterou sua estrutura econômica mediada pela produção da cana de açúcar.

Para a realização do trabalho de campo foi estruturada duas entrevistas. Na primeira, se realizou a coleta de dados em órgãos gestores como os sindicatos rurais, prefeituras municipais e a Empresa de Assistência Técnica e Extensão Rural do Estado de Minas Gerais (EMATER - MG). A realização da segunda entrevista ocorreu com os produtores rurais das unidades territoriais da MRG em questão.

Por intermédio das informações obtidas na EMATER, foram selecionados os produtores por município para serem entrevistados, totalizando $109^{4}$. Destaca-se que o número de entrevistas variou de um município para outro, pois o método de coleta de informações aplicado foi baseado na quantidade de estabelecimentos agropecuários e, estes também são variáveis de uma unidade territorial para outra.

A terceira etapa corresponde à coleta e tabulação de dados secundários pertinentes à MRG de Ituiutaba. Nessa etapa se procurou analisar as informações referentes aos Censos Agropecuários elaborados pelo Instituto Brasileiro de Geografia e Estatística (IBGE), nos anos de 1996 e 2006. Deve-se destacar que

\footnotetext{
${ }^{4}$ Estas entrevistas, tiveram o intuito de verificar se a realidade demonstrada nos dados obtidos, por fontes secundarias, eram compatíveis com a realidade de Microrregião Geográfica de Ituiutaba, visto que o objetivo do trabalho é a verificação do desenvolvimento socioeconômico da MRG citada.
}

foram utilizados os demais bancos de dados do IBGE, como forma de consulta. As transformações procedentes do setor agropecuário entre 1990 a 2014, por intermédio dessa ferramenta. Dessa forma, foram selecionados órgãos que forneceram dados referentes à MRG de Ituiutaba/MG. Além do IBGE, buscaram-se informações na Empresa Brasileira de Pesquisa Agropecuária (EMBRAPA), dentre outros.

Para os procedimentos da pesquisa alguns autores foram fundamentais para a compreensão deste procedimento, dentre eles estão: Bezzi (1985); Pessôa (1999 e 1988); Mazoyer e Roudart (2010); Balsan (2006); Paiva (1976 e 1979); Cargnin (2009); Matos e Pessôa (2011); EMPRAPA (2010), Borges (2007); Ramos (2001); Marouelli (2003); Gonçalves Neto (2000) e Graziano da Silva (1980).

Através da realização dos procedimentos anteriores e do acesso às informações, bem como da análise dos dados se realizou a espacialização, ou seja, a elaboração de cartogramas que representaram a reorganização da agropecuária, ou seja, as transformações ocorridas na MRG de Ituiutaba na escala temporal selecionada. Nessa etapa, a composição ocorreu através do programa Quantum Gis, um software livre. O movimento do programa livre é um meio de compartilhamento do conhecimento tecnológico que teve início na década de 1980, havendo diversos adeptos pelo mundo. Seus maiores defensores são os hackers, um grande número de acadêmicos, cientistas, os mais diferentes combatentes pela causa da liberdade e, mais recentemente, as forças político-culturais que apoiam a distribuição mais equitativa dos benefícios da chamada "Era da informação". (SILVEIRA, 2004, p. 6).

Anteriormente à confecção dos mapas realizou a tabulação dos dados coletados. Para tal, foram necessários alguns cálculos, os quais possibilitaram a confecção de mapas coropléticos. Inicialmente, se realizou o cálculo de Sturges, que tem por objetivo a definição de quantas classes será a composição do mapa. A equação para este cálculo ocorre $K=1+3,3$. 


\section{A ORGANIZAÇÃO ESPACIAL DE ITUIUTABA/MG MEDIADA PELA CULTURA DA CANA DE AÇÚCAR}

logn. Posteriormente se realizaram as avaliações referentes à amplitude total de variação. Por fim, foi executado o cálculo referente à amplitude dos intervalos de classes, que tem por objetivo o resultado dos intervalos que serão elaborados nos cartogramas. Aplicando-se Sturges aos dados selecionados foram definidos três intervalos de classes para a cultura da cana de açúcar nas devidas escalas temporais.

$\mathrm{Na}$ quarta etapa foi efetuado um prognóstico da MRG em estudo, demonstrando a sua reorganização espacial mediada pela produção da cana. $E$, na última fase, como produto final da pesquisa, se realizou a análise e interpretação das informações demonstrando através da espacialização os antigos e novos cenários produtivos presentes na MRG de Ituiutaba.

\section{RESULTADOS E DISCUSSÃO}

Minas Gerais se configurou, no território brasileiro, como um grande produtor agropecuário, contribuindo de forma significativa para a economia do país. Neste sentido, a MRG de Ituiutaba pode ser destacada para demonstrar a importância na produção agrícola do estado de Minas Gerais - MG. Para tal, foram selecionados os dados referentes à cultura da cana de açúcar. De acordo com o IBGE (2014), se observou que a quantidade produzida de cana de açúcar correspondeu a 71.086.808 toneladas, no estado de Minas Gerais.

A produção da cana de açúcar se tornou representativa na MRG em estudo a partir da década de 1990. Entretanto, na década 2000, a mesma se desenvolveu consideravelmente, pois através dos incentivos financeiros e de políticas públicas se instalaram algumas usinas sucroalcooleiras nos municípios, sendo elas: a Cia Energética Vale do São Simão; Santa Vitória Açúcar e Álcool; Unidade Ituiutaba; Unidade Vale do Paranaíba, entre outras. Tendo em vista o número de usinas, que atualmente são em um total de quatro e atrelado aos grandes incentivos por parte do Estado, durante o período de 1970 a 2000 através de programas como o PRODECER, POLOCENTRO e PROALCOOL esta cultura tornouse uma das dinamizadoras do espaço rural desta microrregião. Salienta-se que estas políticas tinham como objetivo desenvolver economicamente, através da produção agropecuária, o bioma Cerrado.

Considerando a importância da cana de açúcar para a Microrregião de Ituiutaba, se faz necessário uma análise referente à sua organização espacial. Desta forma, a partir deste ponto serão tratadas questões referentes à transformação espacial da MRG supracitada, ocasionada pela produção da cana de açúcar. A produção tem aumentado sua área produtiva consideravelmente nos últimos anos. Alguns municípios se destacam no cultivo e colheita desta cultura. Cita-se como exemplo Ituiutaba, que no ano de 1996 tinha uma grande produção. (FIGURA 2).

No ano de 2006 se verifica também uma expansão na produção de açúcar, pois todos os municípios pertencentes a MRG de Ituiutaba cultivava o produto. (FIGURA3). No ano de 2014 é possível verificar algumas mudanças expressivas na organização espacial da cana de açúcar na MRG de Ituiutaba. A cana de açúcar se inseriu na MRG de Ituiutaba através de uma série de fatores que contribuíram significativamente para o desenvolvimento agrícola da Microrregião Geográfica de Ituiutaba. (FIGURA 4). 


\section{A ORGANIZAÇÃO ESPACIAL DE ITUIUTABA/MG MEDIADA PELA CULTURA DA CANA DE AÇÚCAR}

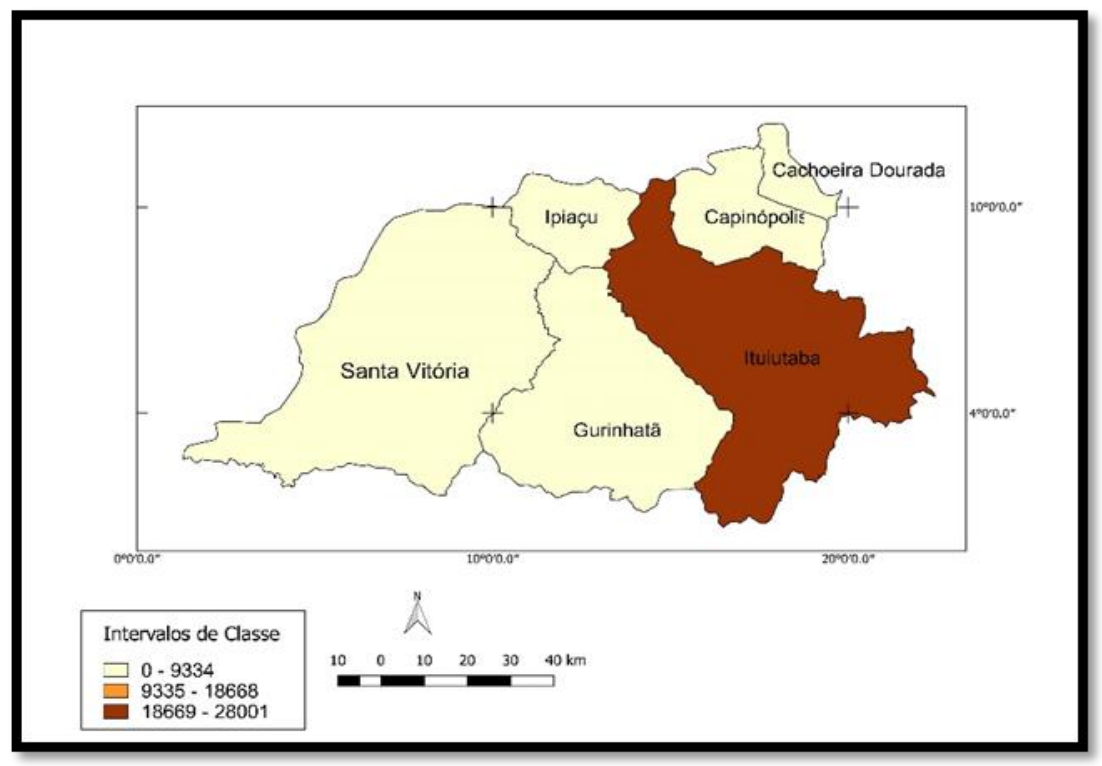

Figura 2 - Regionalização da produção da cana de açúcar (toneladas) na Microrregião Geográfica de Ituiutaba/MG, no ano de 1996

Fonte: Censo Agropecuário do IBGE de 1996.

A produção de cana de açúcar no ano de 1996 se encontrava em fase inicial em alguns municípios, como Cachoeira Dourada e Ipiaçu, embora tivessem área plantada, não tinham colheita e, consequentemente, não existia produção, enquanto outras unidades territoriais produziam de forma modesta.

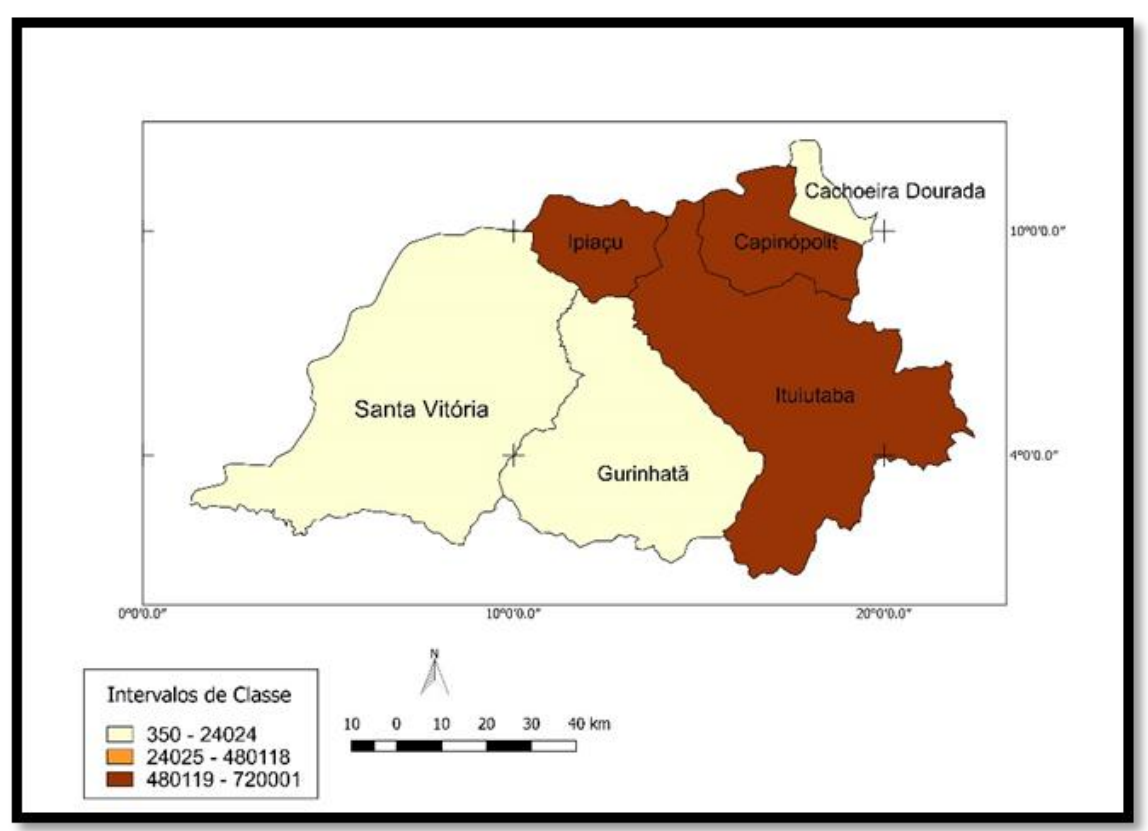

Figura 3 - Regionalização da produção da cana de açúcar (toneladas) na Microrregião Geográfica de Ituiutaba/MG, no ano de 2006

Fonte: IBGE/SIDRA - Pesquisa Agrícola Municipal de 2006. 


\section{A ORGANIZAÇÃo ESPACIAL DE ITUIUTABA/MG MEDIADA PELA CULTURA DA CANA DE AÇÚCAR}

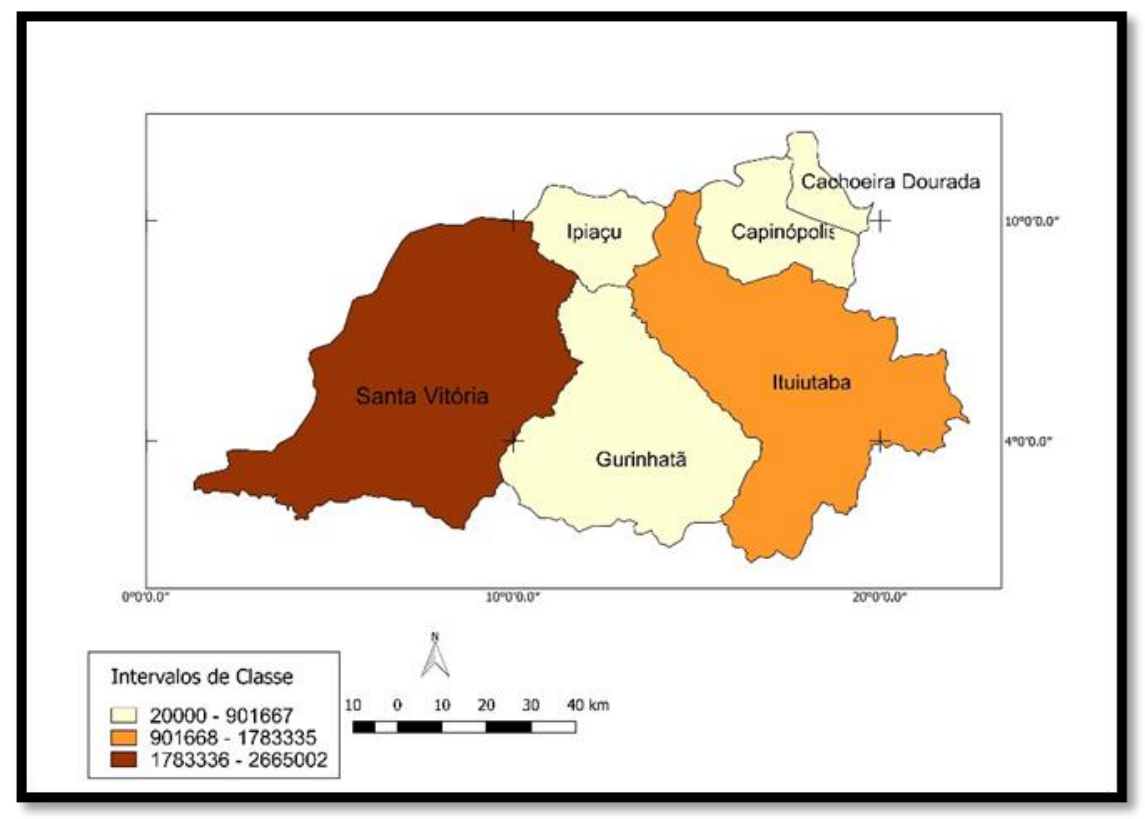

Figura 4 - Regionalização da produção da cana de açúcar (toneladas) na Microrregião Geográfica de Ituiutaba/MG, no ano de 2014

Fonte: IBGE/SIDRA - Pesquisa Agrícola Municipal de 2014.

No ano de 1996 apenas o município de Ituiutaba possuía uma expressiva quantidade de cana de açúcar, as demais unidades territoriais se mantinham estáveis, pois não havia um aumento significativo da sua produção. Já em 2006 é possível verificar uma reorganização espacial, pois Ituiutaba, Capinópolis e Ipiaçu passam a produzir em maior quantidade embora os demais municípios tenham mantido estável sua produção.

Em 2014 há novamente uma transformação do espaço agrário, pois nesse ano é admissível separar a MRG analisada em três grupos, onde Santa Vitória é a maior produtora, seguida de Ituiutaba e, por fim, dos demais municípios.

Apesar da produção de cana de açúcar ser incentivada pelo Estado de 1990 a 1992 os municípios de Cachoeira Dourada, Capinópolis e Ipiaçu não a produziam. Já entre 1993 e 1997, apenas Ipiaçu e Cachoeira Dourada não produziam. Posteriormente, de 1997 a 2004, apenas Cachoeira Dourada não plantava cana de açúcar. A partir de 2005 há uma consolidação na produção da MRG em estudo. Entretanto, se destaca que no ano de 2001 Capinópolis não apresentou quantidade produzida desta gramínea. (TABELA 1).

No ano de 2006, também se verificou um aumento na produção de cana de açúcar na MRG de Ituiutaba, com exceção do município de Santa Vitória, que apresentou decréscimo de produção de cana de açúcar no período de 2002 - 2006, demonstrando uma colheita de 350 toneladas. Entretanto, a partir de 2007 se tem um acréscimo significativo ( 87600 toneladas) pela inserção de agroindústrias sucroalcooleiras no município. A partir deste ano até 2014 a cana de açúcar se torna expressiva no município.

Observando o Mapa 2 e 3, é possível verificar uma reorganização espacial presente nos municípios da MRG em estudo. O município de Ituiutaba tem um aumento na produção de cana de açúcar no ano de 2006, mas não é considerado o maior produtor da MRG de Ituiutaba, sendo este Santa Vitória, onde se tem um aumento de mais de dois milhões de toneladas, pois no ano de 2006 o município apresentava uma quantidade produzida de 350 toneladas. Já em 2014, passa a ter uma produção de 2.665.000 toneladas. Assim, entende-se que esta realidade se tornou possível por conta da demanda de mercado e da inserção de usinas 
SILVEIRA, E. M., ,BEZZI, M. L..

\section{A ORGANIZAÇÃo ESPACIAL DE ITUIUTABA/MG MEDIADA PELA CULTURA DA CANA DE AÇÚCAR}

sucroalcooleiras na unidade territorial em análise. (TABELA 1).

Tabela 1 - Quantidade produzida de cana de açúcar na Microrregião Geográfica de Ituiutaba nos anos de 1990 a 2014

\begin{tabular}{|c|c|c|c|c|c|c|}
\hline \multicolumn{7}{|c|}{ Cana de Açúcar } \\
\hline Ano & $\begin{array}{l}\text { Cachoeira } \\
\text { Dourada }\end{array}$ & Capinópolis & Gurinhatã & Ipiaçu & Ituiutaba & $\begin{array}{c}\text { Santa } \\
\text { Vitória }\end{array}$ \\
\hline 1990 & 0 & 0 & 12250 & 0 & 28000 & 18900 \\
\hline 1991 & 0 & 0 & 2800 & 0 & 21000 & 5600 \\
\hline 1992 & 0 & 0 & 1400 & 0 & 21000 & 5600 \\
\hline 1993 & 0 & 1400 & 1400 & 0 & 21000 & 5600 \\
\hline 1994 & 0 & 1400 & 1400 & 0 & 24000 & 6000 \\
\hline 1995 & 0 & 1400 & 1400 & 0 & 28000 & 3500 \\
\hline 1996 & 0 & 1400 & 1663 & 0 & 28000 & 2800 \\
\hline 1997 & 0 & 1400 & 2100 & 0 & 31500 & 2800 \\
\hline 1998 & 0 & 1400 & 1400 & 1050 & 31500 & 2800 \\
\hline 1999 & 0 & 1400 & 1400 & 1050 & 35000 & 2800 \\
\hline 2000 & 0 & 1400 & 1400 & 1050 & 35000 & 2800 \\
\hline 2001 & 0 & 0 & 1400 & 1400 & 49000 & 4200 \\
\hline 2002 & 0 & 50000 & 1750 & 1400 & 52500 & 350 \\
\hline 2003 & 0 & 204300 & 1750 & 180 & 150000 & 350 \\
\hline 2004 & 0 & 550000 & 2000 & 156100 & 450000 & 350 \\
\hline 2005 & 15000 & 489250 & 2400 & 178500 & 502500 & 350 \\
\hline 2006 & 15000 & 574750 & 2400 & 542215 & 720000 & 350 \\
\hline 2007 & 28500 & 795340 & 2800 & 512720 & 688500 & 87600 \\
\hline 2008 & 40000 & 795340 & 2800 & 512720 & 1589500 & 620000 \\
\hline 2009 & 40069 & 640000 & 255000 & 418403 & 2125000 & 1296000 \\
\hline 2010 & 146080 & 718250 & 342000 & 285000 & 1680000 & 2069360 \\
\hline 2011 & 143706 & 752760 & 342000 & 285000 & 1680000 & 1930400 \\
\hline 2012 & 80000 & 384300 & 218400 & 153360 & 1246200 & 2158400 \\
\hline 2013 & 80000 & 510000 & 218400 & 310980 & 1302000 & 2386400 \\
\hline 2014 & 20000 & 120000 & 373120 & 292500 & 1080000 & 2665000 \\
\hline
\end{tabular}

Fonte: Pesquisa Agrícola Municipal SIDRA/IBGE para os dados de 1990 a 2014.

Em contrapartida, as unidades territoriais de Ipiaçu e Capinópolis, que no ano de 2006 eram grandes produtoras, tendem a diminuir a sua produtividade de cana de açúcar no ano de 2014. Tal acréscimo é justificado pelo avanço da soja e da pecuária bovina nas áreas antes utilizadas com cana de açúcar. Destaca-se que os municípios de Gurinhatã e Ipiaçu se caracterizam como pequenas unidades territoriais e possuem forte ligação com os municípios de sua proximidade. Ipiaçu e Gurinhatã tem sua economia atrelada a de Ituiutaba e de Capinópolis, uma vez que essas duas grandes unidades territoriais diminuem ou apresentam estagnação de sua produção de cana de açúcar. Os municípios de pequeno porte tendem a acompanhá-los, causando uma diminuição em todos os setores econômicos da MRG em análise. (TABELA 1). 


\section{A ORGANIZAÇÃo ESPACIAL DE ITUIUTABA/MG MEDIADA PELA CULTURA DA CANA DE AÇÚCAR}

No período que compreende os anos de 2010 a 2014, passa a ter um decréscimo da produção da cana de açúcar na unidade territorial de Ituiutaba. Entre os motivos deste declínio se cita a falência de um dos principais grupos de usinas sucroalcooleiras, o Grupo Alagoinhas, presentes na MRG supracitada. A quebra desse grupo trouxe inúmeros problemas, entre eles as questões sociais, pois com o declínio da produção da cana de açúcar a mão de obra passou a não receber o seu salário, afetando o mercado local, ou seja, sem poder aquisitivo os trabalhadores não podem consumir os bens e serviços locais.

Em contrapartida, dos anos de 2007 até 2014, a produção da cana de açúcar da Microrregião Geográfica de Ituiutaba passa a aumentar consideravelmente. Um exemplo disso é que no ano de 2005 o município de Ituiutaba produzia cerca de 502.500 toneladas. Em 2009, se teve uma quantidade produzida de 2.125 .000 de toneladas, sendo o ano de maior cultivo no recorte temporal analisado. (QUADRO 1).

Quadro 1 - Quantidade de usinas sucroalcooleiras presentes na Microrregião Geográfica de Ituiutaba/MG, no ano de 2016

\begin{tabular}{|l|l|l|}
\hline \multicolumn{1}{|c|}{ Usina } & \multicolumn{1}{c|}{ Grupo } & \multicolumn{1}{c|}{ Município } \\
\hline Cia Energética Vale do São Simão & Grupo Andrade & Santa Vitória \\
\hline Santa Vitoria Açúcar e Álcool & Dow Química S.A. & Santa Vitória \\
\hline Unidade Ituiutaba & BP Combustíveis & Ituiutaba \\
\hline Unidade Vale do Paranaíba & Grupo João Lyra & Capinópolis \\
\hline
\end{tabular}

Fonte: Trabalho de Campo nos estabelecimentos agropecuários da Microrregião Geográfica de Ituiutaba/MG e web site Nova Cana (2016).

Por ser a MRG de Ituiutaba de grande produtividade, no que tange a cana de açúcar, se faz presente uma quantidade considerável de usinas sucroalcooleiras, que realizam desde o plantio até a transformação deste cultivar em álcool, açúcar, energia entre outros. Destaca-se que é uma das justificativas para a reorganização espacial que ocorreu na MRG, pois através da inserção de usinas os produtores passaram a ser incentivados a produzir a cana de açúcar. É sabido também que essas empresas agrícolas arrendam terras para produzir este cultivar. (QUADRO 1).

O avanço da cana de açúcar para a MRG de Ituiutaba foi fundamental para o seu desenvolvimento econômico, pois esse cultivo proporcionou a inserção de empresas voltadas para o setor, e por consequência, o seu desenvolvimento econômico. Salienta-se que diversos foram os fatores que influenciaram na mudança de cenário das usinas sucroalcooleiras nordestinas, dentre eles se cita a falta de terras para a produção da monocultura da cana de açúcar, a baixa fertilidade dos solos (provenientes dos anos de utilização), a deficiência hídrica e o tipo de topografia. Somadas todas essas dificuldades, ao processo de modernização, foi possível a inserção desse cultivar e de suas industrias no Cerrado, resultando uma transformação no espaço agrário. Essa expansão também está presente na Microrregião Geográfica de Ituiutaba, que se desenvolveu com base nesse tipo de cultura. (OLIVEIRA, 2009, p. 177).

Assim, verifica-se que as políticas voltadas para o estímulo da produção de cana tanto no Cerrado como na MRG em estudo proporcionou situações favoráveis para sua inserção. Cabe destacar que dois fatores culminaram na migração das empresas canavieiras nordestinas para o Cerrado, dentre eles estão o bioma que estava em processo de modernização para a implementação de novas culturas e o seu relevo, propício para a utilização 


\section{A ORGANIZAÇÃO ESPACIAL DE ITUIUTABA/MG MEDIADA PELA CULTURA DA CANA DE AÇÚCAR}

da mecanização, como exposto anteriormente. Salienta-se também que as instalações destas empresas contribuíram para o aumento na quantidade produzida, uma vez que estas realizam um investimento produtivo na MRG em análise.

Outra questão a ser enfatizada é que na MRG de Ituiutaba não há novas áreas a serem ocupadas (fronteiras de expansão) para produzir cana, como foi realizado nas décadas de 1960 e 1970, quando a cana se expandiu avançando para a área central do país, o Cerrado. Dessa maneira, com a diminuição da produção da cana de açúcar, outros cultivares estão ocupando o espaço que outrora era destinado ao seu cultivo. Pode-se destacar a existência de outros fatores para que haja uma reorganização no tipo de produção que se tem na MRG em estudo, entre eles o capital, tanto estrangeiro quanto nacional, ou seja, se verifica a presença de algumas empresas com grande destaque, como exemplo a Monsanto (no município de Cachoeira Dourada), Algar Agronegócios (em Capinópolis), Nestlé (em Ituiutaba) e também a modernização da agricultura e dentre outros fatores.

É importante destacar que o cultivo da cana de açúcar mostra uma dialética nas relações sociais de produção. Ou seja, por um lado, os pequenos proprietários que plantam e entregam sua produção as grandes empresas ficando, portanto, dependentes delas para a compra de seu produto. De outro, as médias e grandes propriedades que acabam, muitas vezes, pressionando os pequenos proprietários para o arrendamento ou vendas de suas unidades produtivas e são as que dinamizam a produção e preço tendo em vista suas relações com o mercado consumidor.

Desta forma, a produção da cana de açúcar apresenta oscilações em sua produção devido a fatores como o mercado, o processo de modernização da agricultura e as dinâmicas agrícolas presentes no país como um todo. Dessa forma, se verifica que na MRG de Ituiutaba que a cana de açúcar, ao longo do recorte temporal analisado, se tornou importante para o seu desenvolvimento econômico e que as mudanças proporcionadas pelo seu cultivo fazem com que as unidades territoriais da MRG em estudo se tornem dinâmicas e competitivas, uma vez que são as principais produtoras do estado de Minas Gerais, proporcionando um desenvolvimento econômico expressivo.

\section{CONSIDERAÇÕES FINAIS}

A Microrregião Geográfica de Ituiutaba é composta por seis municípios com grande representatividade na produção agrícola estadual e nacional. Tem sua economia voltada principalmente para o setor primário, mas também, se fazem presentes as indústrias e agroindústrias que contribuem para o seu desenvolvimento socioeconômico e para sua dinâmica local/regional.

Salienta-se que a MRG em foco passou por diversas mudanças ao longo de sua história, ou seja, o recorte espacial supracitado tem se reorganizado constantemente, principalmente em seu meio agrário, em consequência das exigências impostas pelo capital.

Neste sentido, é importante ressaltar que a reorganização que ocorreu no espaço agrário da MRG de Ituiutaba no período de 1990 a 2014 é proveniente de uma série de fatores, destacando-se a modernização no campo, os incentivos por parte do Estado e de empresas privadas, as dinâmicas de mercado e o próprio desenvolvimento produtivo das unidades territoriais em análise.

No que se refere à modernização do campo se enfatiza que este é resultante principalmente da revolução tecnológica. Através do processo de modernização foi possível a geração de computadores, maquinários e insumos que colaborassem para o aumento na produtividade agrícola nacional, sendo uma realidade também observada na MRG de Ituiutaba. Assim, por intermédio deste avanço tecnológico, foi possível a inserção de maquinários computadorizados, insumos mais potentes e novas técnicas de manejo agrícola no espaço rural.

Alguns fatos históricos devem ser elucidados para uma maior compreensão do 


\section{A ORGANIZAÇÃO ESPACIAL DE ITUIUTABA/MG MEDIADA PELA CULTURA DA CANA DE AÇÚCAR}

processo de metamorfose do espaço agrário da Microrregião de Ituiutaba. Desta forma, cita-se que na década de 1970, se tem o primeiro cultivar de maior destaque, o plantio do arroz. Essa cultura fez com que a MRG analisada ficasse conhecida em todo o país, como a "capital do arroz". Esse tipo de plantio ocorreu apenas por cerca de uma década. Alguns fatores influenciaram para seu curto período produtivo, dentre eles está o tipo de arroz plantado na MRG analisada.

A cana de açúcar é um dos principais plantios do espaço agrário da MRG em análise, devido à implementação das agroindústrias sucroalcooleiras, que visavam o plantio da gramínea, mas também, sua transformação em álcool, energia, açúcar e em outros subprodutos.

Essa cultura teve sua dinâmica espacial relacionada principalmente através de políticas públicas e da inserção de usinas sucroalcooleiras nos municípios analisados. Entretanto, é possível verificar uma maior reorganização espacial deste cultivar, se comparado com a produção da soja, pois na década de 1990 se tinha como maior produtor Ituiutaba. Já em 2006, há inserção de duas novas unidades territoriais, sendo elas Ipiaçu e Capinópolis, e no ano de 2014, apenas Santa Vitória e Ituiutaba passam a produzir a cana de açúcar em grande quantidade.

Ao longo do recorte temporal analisado (1990 a 2014), se podem destacar períodos de maior representatividade na produção agrícola de alguns cultivar. Cita-se o período de 1990 a 2000, onde as produções da soja e da cana de açúcar aumentaram consideravelmente, viabilizadas por ações do Estado e de redes privadas. Na década de 2000, a soja passa a produzir de maneira mais elevada. Porém, esta realidade foi sendo alterada, pois em 2006 a cana de açúcar se mostra como a maior produtora. $\mathrm{Na}$ atualidade se verifica que o cultivar da cana de açúcar tende a diminuir e, em contrapartida, a soja aumenta sua produtividade.

Tendo em vista a extensão territorial da MRG de Ituiutaba e a sua grande produtividade agrícola, se pode afirmar que houve uma reorganização espacial no seu espaço agrário, considerando as exigências do capital. Cita-se, como exemplo, a produção da cana de açúcar e da pecuária bovina no município de Santa Vitória, onde há presença de duas usinas sucroalcooleiras e o número expressivo de cabeças de gado. Essas duas atividades fazem com que haja uma "disputa pelo espaço", ou seja, a cana de açúcar avança cada vez mais na unidade territorial em análise e, em contrapartida, os bovinocultores tendem a permanecer, ocasionado um impedimento no avanço da cana de açúcar. Entretanto, há aqueles produtores que se rendem aos donos das novas usinas sucroalcooleiras e arrendam suas terras para a sua plantação. Enfatiza-se que, apesar dessa disputa, a produtividade tanto da pecuária bovina quanto da produção sucroalcooleira é produzida em grande quantidade.

Na atualidade, a MRG de Ituiutaba tende a reorganizar seu espaço agrário. Cita-se como exemplo, a cana de açúcar, que no período de 2011 a 2015 diminuiu a sua quantidade produzida e, por consequência, sua área plantada. Esse fenômeno ocorre pelo fato de duas grandes agroindústrias sucroalcooleiras entrarem em processo de falência no ano de 2011, sendo que estas estão ligadas ao grupo Alagoinhas. Em contrapartida, com o decréscimo da produção da cana de açúcar, a soja passa a ocupar espaços que antes pertenciam às indústrias sucroalcooleiras.

No que se refere à dinâmica agropecuária da MRG de Ituiutaba, deve ser elucidado três municípios que tendem a produzir em maior quantidade os cultivares e a pecuária, sendo eles: Ituiutaba, Capinópolis e Santa Vitória. Nesse sentido, pode-se afirmar que essas unidades territoriais são as responsáveis pela dinâmica do setor rural da MRG em análise.

Assim, entende-se que diversos fatores ocasionaram a organização/reorganização presente na MRG em estudo, mas que estes tem contribuído para seu o desenvolvimento socioeconômico. Entende-se que analisar esses elementos possibilitou a compreensão histórica e socioeconômica da MRG, pois através, principalmente, da modernização do campo é 


\section{A ORGANIZAÇÃO ESPACIAL DE ITUIUTABA/MG MEDIADA PELA CULTURA DA CANA DE AÇÚCAR}

que foi possível o aumento da produção como também a introdução de novas culturas que são responsáveis pela dinâmica no meio rural da MRG de Ituiutaba, na atualidade.

Nesse contexto, pode-se afirmar que a cana de açúcar teve e tem papel fundamental na dinâmica produtiva da MRG em foco atrelada a presença da soja, que, na atualidade, é a principal cultura e a pecuária de bovinos que sempre esteve presente na sua organização espacial embora esteja diminuindo. Portanto, pode-se afirmar que a estrutura produtiva da microrregião esta baseada na articulação da cana de açúcar, soja e pecuária que em determinados períodos são mais ou menos expressivas, mas que respondem pela dinâmica produtiva deste recorte espacial.

\section{REFERÊNCIAS}

AB'SABER, A. N. A organização natural das paisagens inter e subtropicais brasileiras. In: SIMPÓSIO SOBRE O CERRADO, 3, 1962, São Paulo. Anais... São Paulo: Universidade de São Paulo, 1971.

BEZZI, M. L. São Borja - Transformações no campo agrário: o processo de despecuarização. 1985. 200 p. Dissertação (Mestre em Org. do espaço) Universidade Estadual Paulista Júlio de Mesquita Filho, Rio Claro,1985.

CALAÇA, M.; DIAS, W. A. Modernização do Campo no Cerrado e as transformações socioespaciais em Goiás. Campo - Território: revista de geografia agrária, Uberlândia, v. 5, p. n. 10, p. 312 - 332, $2010 . \quad$ Disponível em: <http://www.seer.ufu.br/index.php/campoterritori o/index>. Acesso em: 10 jan. 2016.

CARGNIN, M. A reorganização do espaço agrário de Júlio de Castilhos/RS: uma nova dinâmica através da lavoura empresarial da soja. 164 p. Dissertação (Mestrado em Geografia) Universidade Federal de Santa Maria, Santa Maria, 2009.
CLEPS JR, J. Dinâmica e estratégias do setor agroindustrial no cerrado: o caso do Triângulo Mineiro. 1998. 256 f. Tese (Doutorado em Geografia) - Universidade Estadual Paulista, Rio Claro, 1998.

CORRÊA, R. L. Região e Organização Espacial. 7. ed. São Paulo: Ática, 2007.

DINIZ, B. P. C. O Grande Cerrado do Brasil Central: geopolítica e economia. 2006. 231 f. Tese (Doutor em Geografia) - Universidade de São Paulo, São Paulo, 2006.

INSTITUTO BRASILEIRO DE GEOGRAFIA E ESTATÍSTICA - IBGE. Enciclopédia dos Municípios Brasileiros. 1959, 475 p. Disponível em: <http://biblioteca.ibge.gov.br/visualizacao/dtbs/ minasgerais/ituiutaba.pdf>. Acesso em: 10 jan. 2016.

MATOS, P. F.; PESSÔA, V. L. S. A modernização da agricultura no Brasil e os novos usos do território. Revista Geo UERJ, Rio de Janeiro, v. 2, n. 22, p. 290 - 322, 2011. Disponível em: <http:/ /www.epublicacoes.uerj.br/ index.php/ geouerj>. Acesso em: 15 de ago. 2015.

MAZOYER, M.; ROUDART, L. História das agriculturas no mundo: do neolítico à crise contemporânea. Tradução da Cláudia F. FalluhBaluino Ferreira. São Paulo: UNESP, 2010. 568p. Tradução de: Histoire des agricultores du monde.

OLIVEIRA, A. M. S. de. Reordenamento territorial e produtivo do agronegócio canavieiro no Brasil e os desdobramentos para o trabalho. 2009. $597 \mathrm{f}$. Tese (Doutorado em Geografia) - Universidade Estadual Paulista, Presidente Prudente, 2009.

OLIVEIRA, B. S. de. Ituiutaba na rede urbana Tijuana: (re) configurações sócio-espaciais de 1950 a 2003. 2003. 208 p. Dissertação (Mestrado em Geografia) - Universidade Federal de Uberlândia, Uberlândia, 2003. 


\section{A ORGANIZAÇÃo ESPACIAL DE ITUIUTABA/MG MEDIADA PELA CULTURA DA CANA DE AÇÚCAR}

OLIVEIRA, H. C. M. de. Urbanização e Cidades: análise da Microrregião Geográfica de Ituiutaba (MG). 2013. 431 f. Tese (Doutor em Geografia) Universidade Federal de Uberlândia, Uberlândia, 2013.

PAIVA, R. M. Modernização e dualismo tecnológico na agricultura: uma reformulação. Revista Pesquisa Planejamento Econômico, Rio de Janeiro, v.1, n. 5, p. 117 - 161, jun. 1975. Disponível em: <http://www.ppe.ipea.gov.br/index.php/ppe/articl e/viewFile/656/598>. Acesso em: 15 nov. 2015.

PAIVA, R. M.; SCHATTAN, S.; FREITAS, C. F. T. de. Setor agrícola do Brasil: comportamento econômico, problemas e possibilidades. 2. ed. Rio de Janeiro: Forense - Universitária, 1976.

PESSÔA, V. L. S. Ação do Estado e as transformações agrárias no Cerrado das Zonas de Paracatu e Alto Paranaíba - MG. 1988. 239 f. Tese (Doutorado em Geografia) - Universidade Estadual Paulista Júlio de Mesquita Filho", Rio Claro, 1988.
PESSÔA, V. L. S. Geografia e pesquisa qualitativa: um olhar sobre o processo investigativo. Geo UERJ, v. 1 , n. 23, p. 4 - 18, 2012. Disponível em: <http://www.e-

publicacoes.uerj.br/index.php/geouerj/article/view /3682>. Acesso em: 10 nov. 2015.

SILVEIRA, S. A. Software livre: a luta pela liberdade do conhecimento. São Paulo: Perseu Abramo, 2004, 80 p. Disponível em: <http://www.fpabramo.org.br/ uploads/Software_livre.pdf>. Acesso em 20 set. 2014.

SOUTO, T. S. Agroindústria leiteira no município de Ituiutaba - MG: organização/reorganização socioespacial no período de 1960 a 2013. 2016. 143 p. Dissertação (Mestrado em Geografia) Universidade Federal de Santa Maria, Santa Maria, 2016. 